\title{
Sex Differences in Short- and Long-Term Survival Among Critically III Patients with Sepsis
}

This article was published in the following Dove Press journal:

International Journal of General Medicine

\section{Shan Lin (1D* \\ Wanmei He* \\ Zixuan $\mathrm{Hu}$ \\ Lihong Bai \\ Mian Zeng}

Department of Medical Intensive Care Unit, The First Affiliated Hospital, Sun Yat-Sen University, Guangzhou,

Guangdong, People's Republic of China

*These authors contributed equally to this work
Correspondence: Mian Zeng

Department of Medical Intensive Care Unit,

The First Affiliated Hospital, Sun Yat-Sen

University, No. 58 Zhongshan Road 2,

Guangzhou, Guangdong, 510080, People's

Republic of China

Email zengmian@mail.sysu.edu.cn
Background: Currently, there have been studies showing a correlation between sex differences and prognosis. Nevertheless, the conclusions of clinical studies on sex-based differences are controversial. We aimed to evaluate the effect of sex on the short- and long-term survival of critically ill patients with sepsis.

Methods: We use the critical care database of the healthcare information mart. Cox models were conducted to determine the relationship of 28-day and 1-year mortality with a different sex. Interaction and stratified analyses were conducted to test whether the effect of sex differed across age and sequential organ failure assessment (SOFA) score subgroups.

Results: A total of 12,321 patients were enrolled in this study. The Cox regression analysis showed that the 28-day and 1-year mortality rates of female patients were significantly lower than those of male patients by $10 \%$ and $8 \%$, respectively (hazard ratio $[\mathrm{HR}]=0.90,95 \%$ confidence interval $[\mathrm{CI}] 0.83-0.98$, and $\mathrm{HR}=0.92,95 \%$ CI $0.87-0.97$, respectively). The effects of the association between sex and 28-day and 1-year mortality were broadly consistent for age and the SOFA subgroup variables. Only age was observed to have significant interactions in the 1 -year mortality $(P=0.0177)$. Compared with male patients, female patients aged $<50$ years had a long-term survival advantage (HR $=0.77,95 \% \mathrm{CI}$ 0.62-0.95). In contrast, we did not find sex-based differences in the short- and long-term survival for patients aged $\geq 50$ years.

Conclusion: In the current retrospective large database review, the 28-day and 1-year mortality were significantly lower in females than in male patients among critically ill patients with sepsis. Notably, there was an interaction between age and sex, and whether female-associated hormones or other contributing factors affect the clinical outcomes of patients with sepsis needs to be further researched.

Keywords: critical care, sepsis, sex, prognosis

\section{Introduction}

Sepsis, a severe organ dysfunction induced by infection, is one of the leading causes of intensive care unit (ICU) admissions. ${ }^{1}$ It is among the most expensive conditions to treat and a leading cause of death in United States hospitals. Sepsis affects more than 19 million people each year. ${ }^{2}$ In 2014, approximately 174,000 adults in the United States were hospitalized for sepsis, $69.9 \%$ of whom were aged 60 years or older. ${ }^{3,4}$

Sex is one of the many factors postulated to affect the outcomes of sepsis in patients, with a hypothesis that females have better immune system activity and lower mortality rates than males. Indeed, several experimental and clinical studies have indicated such sex-based differences. In an animal model of sepsis, the 
survival rate and immune system response of pre-estrus female mice were significantly higher than those of male mice. ${ }^{5}$ Similarly, the survival rate of male mice with sepsis significantly increased after androgen receptor blockade. ${ }^{6}$ In contrast to animal research, numerous clinical studies have found no sex-based differences ${ }^{7-9}$ or a higher mortality risk in males ${ }^{10,11}$ or in females. ${ }^{12-14}$ At present, the conclusions of clinical studies on sexbased differences are controversial. Therefore, determining the association between sex and mortality in sepsis could provide an impetus for exploring its pathophysiological mechanism. If such an association exists, the hormonal status (ie, androgen and estrogen) of a patient with sepsis should be considered. In addition, this knowledge could lead to development of potential therapies. Although many studies have explored the association between sex and the prognosis of sepsis, it should be investigated in different populations in order to obtain more convincing evidence. In the present study, we aimed to determine the effect of sex on the clinical outcomes of critically ill patients with sepsis.

\section{Patients and Methods}

\section{Patient Data}

We conducted this study in the Medical Information Mart for Intensive Care III database (version: 1.4). ${ }^{15}$ The institutional review boards of Beth Israel Deaconess Medical Center and Massachusetts Institute of Technology Affiliates authorized access to the database (Shan Lin, Record ID: 33,460,949). Due to the anonymized nature of the data, the informed consent of the patient was not required.

All patients ( $\geq 18$ years) with a diagnosis of sepsis based on a sequential organ failure assessment (SOFA) score $\geq 2$ and suspected infection within the first day of ICU admission were included, and the extraction code for sepsis-3 we used was identified by Johnson et $\mathrm{al}^{1,16}$. Patients whose follow-up were less than one day were excluded. Only the data from the first ICU admission were analyzed. In keeping with our previous studies, we extracted data using structured query language (SQL) with Navicat. ${ }^{17-19}$ The code is also readily available on the publicly accessed website. $^{20}$

\section{Outcomes}

The primary outcomes were the 28-day and 1-year mortality rates after ICU admission.

\section{Statistical Analysis}

Data were presented as mean \pm standard deviation or median (interquartile range, IQR) for continuous variables and as numbers and percentages for categorical variables. Characteristics of the participants in male and female groups were compared using the Chi-square test for categorical variables and Fisher's exact test or Kruskal-Wallis test for continuous variables. Different Cox regression models were conducted to determine the independent relationships of 28-day and 1-year mortality rates with a different sex. In the model I, covariates were adjusted for age, infection site, SOFA, mechanical ventilation on first day, renal replacement therapy on first day, Elixhauser Comorbidity Index (SID30). ${ }^{21}$ In model II, the same as model I, but we replaced SID30 with specific comorbidities, including congestive heart failure, chronic pulmonary disease, valvular disease, peripheral vascular disease, hypertension, diabetes, liver disease, renal failure, AIDS, lymphoma, tumor, obesity, alcohol abuse, and drug abuse. In model III, we used propensity score for adjustment calculated by age, infection site, SOFA, mechanical ventilation on first day, renal replacement therapy on first day, congestive heart failure, chronic pulmonary disease, valvular disease, peripheral vascular disease, hypertension, diabetes, liver disease, renal failure, AIDS, lymphoma, tumor, obesity, alcohol abuse, and drug abuse. The results of the main analysis were used with multivariate Cox regression models. Interaction and stratified analyses were conducted to test whether the effect of sex differed across subgroup variables classified by age $(<50$ and $\geq 50)$ and SOFA $(<5,5-10,10-15, \geq 15)$. EmpowerStats(R) (www.empowerstats.com, $\mathrm{X} \& \mathrm{Y}$ solutions, Inc., Boston, MA, USA) and R (http://www.R-project.org, version 3.4.3) were used for data analysis. $P$-values $<0.05$ were considered significant.

\section{Results}

\section{Characteristics of Participants}

We included 12,321 patients in this study. As shown in Table 1, there were 6493 male and 5828 female patients, accounting for $52.7 \%$ and $47.3 \%$, respectively. Female patients were older than male patients $(68.99 \pm 16.46$ vs $65.42 \pm 16.20, P<0.001)$. Statistical differences were found between male and female patients in the SID30, infection site, and the need for mechanical ventilation or renal replacement therapy on the first day of ICU admission. The median SOFA scores were the same in the two groups, 
Table I Characteristics of Participants

\begin{tabular}{|c|c|c|c|c|}
\hline Variables & All $(N=\mid 2,321)$ & Male $(\mathrm{N}=6493)$ & Female $(\mathrm{N}=5828)$ & $P$-value \\
\hline Age (years) & $67.10 \pm 16.42$ & $65.42 \pm 16.20$ & $68.99 \pm 16.46$ & $<0.001$ \\
\hline SOFA & $5.00(3.00-7.00)$ & $5.00(3.00-7.00)$ & $5.00(3.00-7.00)$ & $<0.001$ \\
\hline Elixhauser Comorbidity Index (SID30) & $17.00(8.00-26.00)$ & $17.00(8.00-26.00)$ & $16.00(8.00-25.00)$ & 0.005 \\
\hline Infection site & & & & $<0.001$ \\
\hline Bloodstream & $5440(44.15 \%)$ & $2966(45.68 \%)$ & $2474(42.45 \%)$ & \\
\hline Pulmonary & 807 (6.55\%) & 459 (7.07\%) & $348(5.97 \%)$ & \\
\hline Abdominal & $265(2.15 \%)$ & $137(2.11 \%)$ & $128(2.20 \%)$ & \\
\hline Urinary tract & $2596(21.07 \%)$ & $1210(18.64 \%)$ & $1386(23.78 \%)$ & \\
\hline Others & $3213(26.08 \%)$ & $|72|(26.5 \mid \%)$ & $1492(25.60 \%)$ & \\
\hline Mechanical ventilation on first day & $6132(49.77 \%)$ & $3357(51.70 \%)$ & $2775(47.61 \%)$ & $<0.001$ \\
\hline Renal replacement therapy on first day & $604(4.90 \%)$ & $349(5.38 \%)$ & $255(4.38 \%)$ & 0.010 \\
\hline Length of ICU stay (days) & $3.33(1.83-7.86)$ & $3.55(1.83-8.57)$ & $3.18(1.82-7.14)$ & $<0.001$ \\
\hline Length of hospital stay (days) & $10.85(6.36-19.04)$ & II.68 (6.74-20.36) & $10.04(6.07-17.84)$ & $<0.001$ \\
\hline 28-year mortality, n (\%) & $2263(18.37 \%)$ & 1206 (I8.57\%) & 1057 (I8.14\%) & 0.531 \\
\hline I-year mortality, n (\%) & $4615(37.46 \%)$ & $2418(37.24 \%)$ & $2197(37.70 \%)$ & 0.601 \\
\hline \multicolumn{5}{|l|}{ Comorbidities, n (\%) } \\
\hline Congestive heart failure & $4168(33.83 \%)$ & $2226(34.28 \%)$ & 1942 (33.32\%) & 0.260 \\
\hline Chronic pulmonary disease & $2716(22.04 \%)$ & I458 (22.45\%) & $1258(2 \mid .59 \%)$ & 0.245 \\
\hline Valvular disease & 1747 (14.18\%) & 909 (I4.00\%) & 838 (I4.38\%) & 0.547 \\
\hline Peripheral vascular disease & $141 \mid(\mid 1.45 \%)$ & 720 (II.09\%) & 691 (11.86\%) & 0.182 \\
\hline Hypertension & $6522(52.93 \%)$ & $3385(52.13 \%)$ & $3137(53.83 \%)$ & 0.060 \\
\hline Diabetes & $3509(28.48 \%)$ & 1817 (27.98\%) & $1692(29.03 \%)$ & 0.198 \\
\hline Liver disease & $1258(10.21 \%)$ & $669(10.30 \%)$ & $589(10.11 \%)$ & 0.718 \\
\hline Renal failure & $2226(18.07 \%)$ & $1149(17.70 \%)$ & 1077 (I8.48\%) & 0.259 \\
\hline AIDS & $180(1.46 \%)$ & $94(1.45 \%)$ & $86(1.48 \%)$ & 0.897 \\
\hline Lymphoma & $309(2.51 \%)$ & $163(2.51 \%)$ & $146(2.51 \%)$ & 0.985 \\
\hline Tumor & 647 (5.25\%) & 337 (5.19\%) & 310 (5.32\%) & 0.749 \\
\hline Obesity & 708 (5.75\%) & $335(5.16 \%)$ & $373(6.40 \%)$ & 0.003 \\
\hline Alcohol abuse & 923 (7.49\%) & 490 (7.55\%) & 433 (7.43\%) & 0.806 \\
\hline Drug abuse & 405 (3.29\%) & $220(3.39 \%)$ & $185(3.17 \%)$ & 0.506 \\
\hline
\end{tabular}

Note: Data were presented as mean \pm standard deviation or median (interquartile range, IQR) for continuous variables and as numbers and percentages for categorical variables.

Abbreviations: ICU, intensive care unit; SOFA, sequential organ failure assessment; AIDS, acquired immune deficiency syndrome. 
Table 2 Cox Regression Analysis for Sex Differences with 28-Day and I-Year Mortality

\begin{tabular}{|c|c|c|c|c|}
\hline \multicolumn{5}{|l|}{ Clinical Outcome } \\
\hline 28-Day Mortality & Sex & HR & $95 \% \mathrm{Cl}$ & $P$-value \\
\hline Crude & $\begin{array}{l}\text { Male } \\
\text { Female }\end{array}$ & $\begin{array}{l}1.0 \\
0.98\end{array}$ & $\begin{array}{l}- \\
0.90-1.06\end{array}$ & $\begin{array}{l}- \\
0.6248\end{array}$ \\
\hline Model I & $\begin{array}{l}\text { Male } \\
\text { Female }\end{array}$ & $\begin{array}{l}1.0 \\
0.97\end{array}$ & $\begin{array}{l}- \\
0.89-1.05\end{array}$ & $\begin{array}{l}- \\
0.4093\end{array}$ \\
\hline Model II & $\begin{array}{l}\text { Male } \\
\text { Female }\end{array}$ & $\begin{array}{l}1.0 \\
0.90\end{array}$ & $\begin{array}{l}- \\
0.83-0.98\end{array}$ & $\begin{array}{l}- \\
0.0148\end{array}$ \\
\hline Model III & $\begin{array}{l}\text { Male } \\
\text { Female }\end{array}$ & $\begin{array}{l}1.0 \\
0.91\end{array}$ & $\begin{array}{l}- \\
0.83-1.00\end{array}$ & $\begin{array}{l}- \\
0.0450\end{array}$ \\
\hline I-Year Mortality & Sex & HR & $95 \% \mathrm{Cl}$ & $P$-value \\
\hline Crude & $\begin{array}{l}\text { Male } \\
\text { Female }\end{array}$ & $\begin{array}{l}1.0 \\
1.01\end{array}$ & $\begin{array}{l}- \\
0.96-1.07\end{array}$ & $\begin{array}{l}- \\
0.6413\end{array}$ \\
\hline Model I & $\begin{array}{l}\text { Male } \\
\text { Female }\end{array}$ & $\begin{array}{l}1.0 \\
0.95\end{array}$ & $\begin{array}{l}- \\
0.90-1.01\end{array}$ & $\begin{array}{l}- \\
0.1155\end{array}$ \\
\hline Model II & $\begin{array}{l}\text { Male } \\
\text { Female }\end{array}$ & $\begin{array}{l}1.0 \\
0.92\end{array}$ & $\begin{array}{l}- \\
0.87-0.97\end{array}$ & $\begin{array}{l}- \\
0.0048\end{array}$ \\
\hline Model III & $\begin{array}{l}\text { Male } \\
\text { Female }\end{array}$ & $\begin{array}{l}1.0 \\
0.94\end{array}$ & $\begin{array}{l}- \\
0.89-1.00\end{array}$ & $\begin{array}{l}- \\
0.0474\end{array}$ \\
\hline
\end{tabular}

Notes: Model I adjust for: age (years), infection site, SOFA, mechanical ventilation on first day, renal replacement therapy on first day, SID30. Model II adjust for: age (years), infection site, SOFA, mechanical ventilation on first day, renal replacement therapy on first day, congestive heart failure, chronic pulmonary disease, valvular disease, peripheral vascular disease, hypertension, diabetes, liver disease, renal failure, AIDS, lymphoma, tumor, obesity, alcohol abuse, and drug abuse. Model III was adjusted by propensity score calculated by age (years), infection site, SOFA, mechanical ventilation on first day, renal replacement therapy on first day, congestive heart failure, chronic pulmonary disease, valvular disease, peripheral vascular disease, hypertension, diabetes, liver disease, renal failure, AIDS, lymphoma, tumor, obesity, alcohol abuse, and drug abuse.

Abbreviations: $\mathrm{HR}$, hazard ratio; $\mathrm{Cl}$, confidence interval.

but the median SID30 score was higher in male than in female patients. In all patients, the most common infection site was the bloodstream, and female patients had a higher rate of urinary tract infections than male patients. There were significantly more male than female patients who required mechanical ventilation and renal replacement therapy on the first day of ICU admission. Hypertension was the most common comorbidity among all patients, accounting for $52.93 \%$. Other detailed results are listed in Table 1.

\section{Clinical Outcomes of Participants}

In terms of clinical outcomes, the median length of hospital and ICU stay was greater in male than in female patients. The 28-day mortality rate was slightly higher (18.57\% vs $18.14 \%)$, and the 1 -year mortality rate was slightly lower in male patients than in female patients (37.24\% vs $37.70 \%$ ); however, these differences were not statistically significant (all $P>0.05$; Table 1 ).

\section{Associations Between Sex-Based Differences and Short- and Long-Term Survival}

The multivariable Cox regression analysis showed that the 28-day and 1-year mortality rates of female patients were significantly lower than those of male patients by $10 \%$ and $8 \%$, respectively (hazard ratio $[\mathrm{HR}]=0.90,95 \%$ confidence interval [CI] $0.83-0.98, P=0.0148$ and $\mathrm{HR}=0.92,95 \% \mathrm{CI}$ $0.87-0.97, P=0.0048$, respectively; Table 2 ).

In the stratified analysis, the effects of the association between sex and 28-day and 1-year mortality were broadly consistent for age and the SOFA subgroup variables (Table 3 and Figures 1-4). Only age was observed to have significant interactions in the 1 -year mortality $(P=0.0177)$. Compared with male patients, female patients aged $<50$ years had a long-term survival advantage $(\mathrm{HR}=0.77,95 \%$ CI $0.62-$ $0.95, P=0.0163$; Figure 3 ). In contrast, we did not find sexbased differences in the short- and long-term survival for patients aged $\geq 50$ years. 
Table 3 Effect Size of Sex Difference in 28-Day and I-Year Mortality in Prespecified and Exploratory Subgroups in Each Subgroup

\begin{tabular}{|c|c|c|c|c|c|c|}
\hline \multirow[b]{3}{*}{ Subgroup Variables } & \multicolumn{6}{|l|}{ Adjusted Model } \\
\hline & \multicolumn{3}{|c|}{ 28-Day Mortality } & \multicolumn{3}{|l|}{ I-Year Mortality } \\
\hline & HR $(95 \% \mathrm{Cl})$ & $P$-value & $P$ for Interaction & HR (95\% Cl) & $P$-value & $P$ for Interaction \\
\hline \multicolumn{7}{|l|}{ Age (years): $<50$} \\
\hline Male & 1.0 & - & 0.0653 & 1.0 & - & 0.0177 \\
\hline Female & $0.77(0.57-1.06)$ & 0.1048 & & $0.77(0.62-0.95)$ & 0.0163 & \\
\hline \multicolumn{7}{|l|}{ Age (years): $\geq 50$} \\
\hline Male & 1.0 & - & & 1.0 & - & \\
\hline Female & $1.05(0.96-1.14)$ & 0.3098 & & $1.04(0.98-1.10)$ & 0.2354 & \\
\hline \multicolumn{7}{|l|}{ SOFA: $<5$} \\
\hline Male & 1.0 & - & 0.2916 & 1.0 & - & 0.8577 \\
\hline Female & $0.90(0.78-1.04)$ & 0.1668 & & $0.95(0.86-1.04)$ & 0.2295 & \\
\hline \multicolumn{7}{|l|}{ SOFA: $\geq 5,<10$} \\
\hline Male & 1.0 & - & & 1.0 & - & \\
\hline Female & $0.91(0.80-1.03)$ & 0.1186 & & $0.92(0.84-1.00)$ & 0.0578 & \\
\hline \multicolumn{7}{|l|}{ SOFA: $\geq 10,<15$} \\
\hline Male & 1.0 & - & & 1.0 & - & \\
\hline Female & $1.13(0.92-1.38)$ & 0.2448 & & $1.01(0.85-1.21)$ & 0.8806 & \\
\hline \multicolumn{7}{|l|}{ SOFA: $\geq 15$} \\
\hline Male & 1.0 & - & & 1.0 & - & \\
\hline Female & I.03 (0.59-I.79) & 0.9166 & & $1.03(0.62-1.69)$ & 0.9200 & \\
\hline
\end{tabular}

Notes: Adjust for age (years), infection site, SOFA, mechanical ventilation on first day, renal replacement therapy on first day, congestive heart failure, chronic pulmonary disease, valvular disease, peripheral vascular disease, hypertension, diabetes, liver disease, renal failure, AIDS, lymphoma, tumor, obesity, alcohol abuse, and drug abuse except for the subgroup variable.

Abbreviations: HR, hazard ratio; $\mathrm{Cl}$, confidence interval.

Figure 5 shows the effect of age (continuous variable) by sex on the 28-day and 1-year mortality in patients with sepsis. The results suggested that the 1-year mortality was predominantly lower in female than in male patients at different ages (Figure 5B), while between the age of 50 and 60 years, the 28-day mortality was slightly higher in female than in male patients (Figure 5A). Figure 6 shows the effect of different SOFA groups on the 28-day and 1-year mortality of patients with sepsis by sex, indicating that female patients had lower 1-year mortality than male patients in each SOFA group (Figure 6B); however, the 28-day mortality was slightly higher in female than in male patients with a SOFA score of 10 to 15 (Figure 6A).

\section{Discussion}

This retrospective cohort study including 12,321 patients compared the association between sex and the 28-day as well as 1-year mortality. To date, many studies have explored this association. However, there is still no consensus, which is confusing for clinicians. Therefore, it is necessary to perform such research in different populations, which would be particularly beneficial if using a large database. In our study, among critically ill patients with sepsis, female patients had significantly lower 28-day and 1-year mortality rates than male patients. Moreover, unlike previous studies, we found an interaction between age and sex, indicating that female patients aged $<50$ years had a survival advantage compared with male patients.

In humans, sex-based differences have been reported in many diseases, such as hypertension, atherosclerosis, lung disease, and cardiovascular disease. ${ }^{22-27}$ However, sexbased differences in terms of infection and sepsis have remained controversial. A large retrospective study that enrolled 10,422,301 adult patients with sepsis indicated that male patients had higher mortality rates than female patients (odds ratio $[\mathrm{OR}]=1.09,95 \%$ CI $1.05-1.14$ ). ${ }^{10}$ Similarly, a prospective study by Adrie et al involving 1692 patients with severe sepsis revealed that female patients had lower hospital mortality rates than male patients $(\mathrm{OR}=0.75$, 95\% CI 0.57-0.97), but such results 


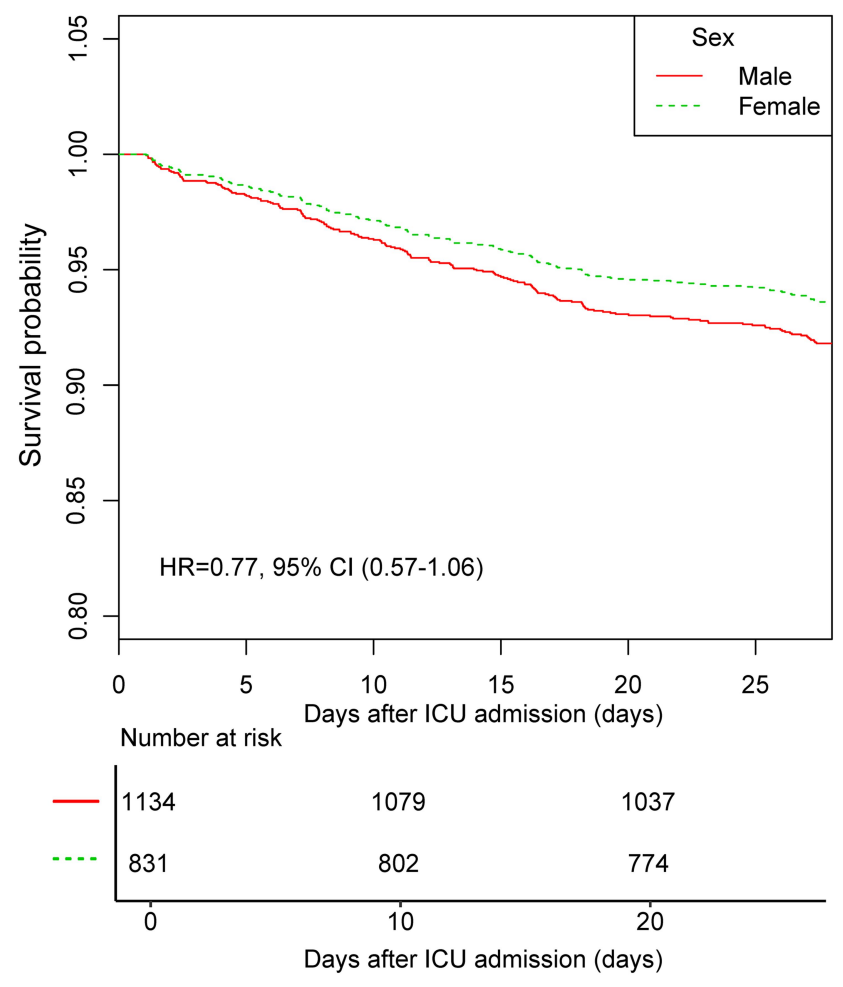

Figure I The 28-day survival curve of the Cox regression model for participants with age $<50$ years.

Notes: The Cox regression model for 28-day mortality in female patients $<50$ years of age compared to male patients had a result of $\mathrm{HR}=0.77$ ( $95 \% \mathrm{Cl} 0.57-1.06)$, after adjusting for age (years), infection site, SOFA, mechanical ventilation on first day, renal replacement therapy on first day, congestive heart failure, chronic pulmonary disease, valvular disease, peripheral vascular disease, hypertension, diabetes, liver disease, renal failure, AIDS, lymphoma, tumor, obesity, alcohol abuse, and drug abuse.

Abbreviations: $\mathrm{HR}$, hazard ratio; $\mathrm{Cl}$, confidence interval; ICU, intensive care unit; SOFA, sequential organ failure assessment; AIDS, acquired immune deficiency syndrome.

were only observed in patients over the age of 50 $(\mathrm{OR}=0.69,95 \%$ CI $0.52-0.93) .{ }^{11}$ This may be attributed to the fact that there were only 127 female and 222 male patients under 50 years of age in the study population. Additionally, the female sex hormone, ie, estrogen, exhibits a modulatory effect on the immune system that may contribute to the benefit of females during sepsis; however, its levels start decreasing after the age of $50 .{ }^{28-30}$ In our study, the results of the subgroup analysis were contrary to those of Adrie et al; namely, we found that only female patients under the age of 50 had a survival advantage compared with male patients.

A prospective study with 327 patients with sepsis found in the subgroup analysis that an increase in mortality was related to the female sex. ${ }^{12}$ Eachempati et al also suggested that female sex was an independent index of increased mortality in critically ill patients. ${ }^{13}$ However, both of these studies had small sample sizes. ${ }^{12,13}$

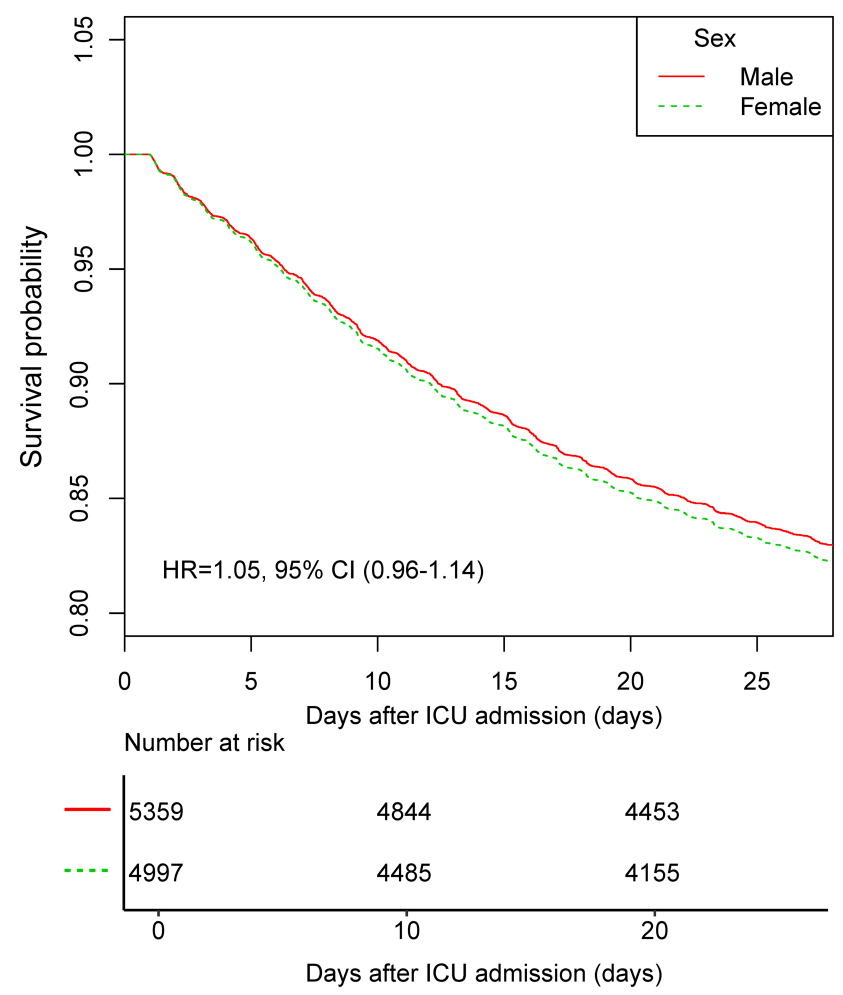

Figure 2 The 28-day survival curve of the Cox regression model for participants with age $\geq 50$ years.

Notes: The Cox regression model for 28-day mortality in female patients $\geq 50$ years of age compared to male patients had a result of $H R=1.05(95 \% \mathrm{Cl} 0.96-1.14)$, after adjusting for age (years), infection site, SOFA, mechanical ventilation on first day, renal replacement therapy on first day, congestive heart failure, chronic pulmonary disease, valvular disease, peripheral vascular disease, hypertension, diabetes, liver disease, renal failure, AIDS, lymphoma, tumor, obesity, alcohol abuse, and drug abuse.

Abbreviations: $\mathrm{HR}$, hazard ratio; $\mathrm{Cl}$, confidence interval; ICU, intensive care unit; SOFA, sequential organ failure assessment; AIDS, acquired immune deficiency syndrome.

Another large retrospective cohort study including 18,757 patients with severe sepsis/septic shock demonstrated that female patients had higher in-hospital mortality rates than male patients. Nonetheless, the subgroup analysis found that, compared with male patients, female patients younger than 50 years did not have an increased risk of death, which is consistent with the findings of our study. ${ }^{14}$ Additionally, some studies have demonstrated that no sexbased differences exist in patients with sepsis. ${ }^{7-9}$

Although the underlying physiological mechanisms for these sex-based differences are still not fully understood, there are several possible explanations. Theoretically based explanations focus on the differences in hormone levels between males and females. Namely, the balancing effect of estrogen on the regulation of the immune system and its protective effect on endothelial cells have been well documented. ${ }^{28-32}$ Moreover, improved survival has been demonstrated after androgen receptor blockade in animal 


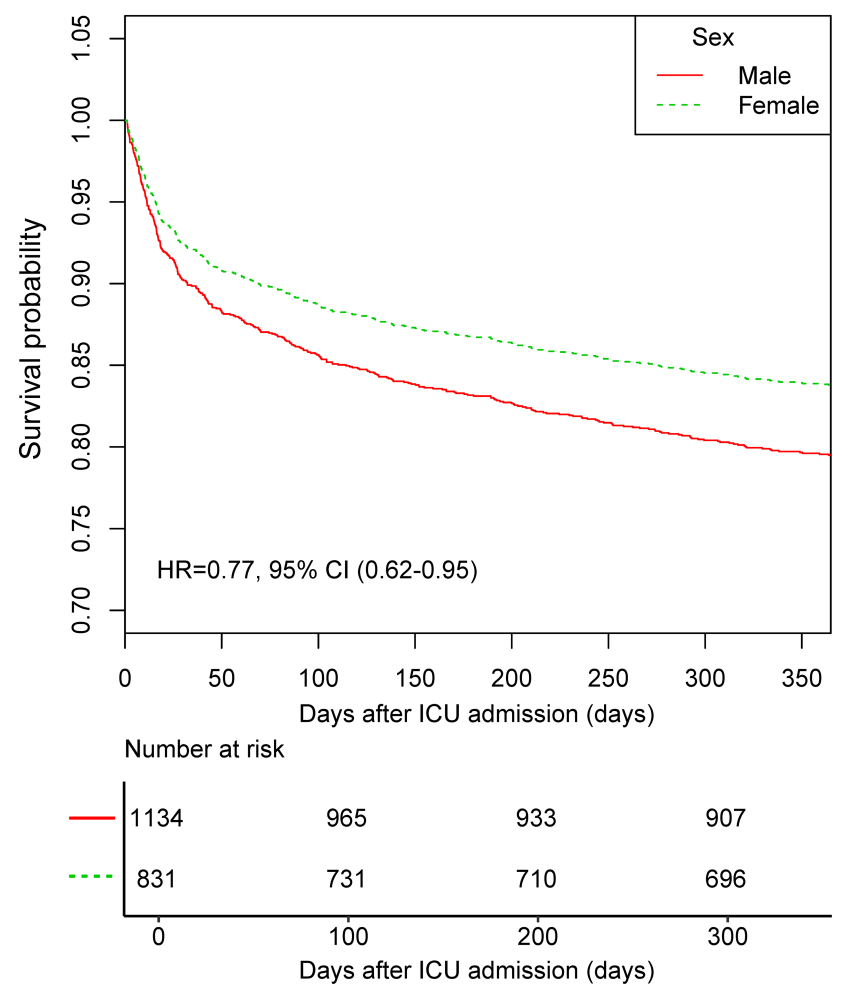

Figure 3 The I-year survival curve of the Cox regression model for participants with age $<50$ years.

Notes: The Cox regression model for I-year mortality in female patients $<50$ years of age compared to male patients had a result of $\mathrm{HR}=0.77(95 \% \mathrm{Cl} 0.62-0.95)$, after adjusting for age (years), infection site, SOFA, mechanical ventilation on first day, renal replacement therapy on first day, congestive heart failure, chronic pulmonary disease, valvular disease, peripheral vascular disease, hypertension, diabetes, liver disease, renal failure, AIDS, lymphoma, tumor, obesity, alcohol abuse, and drug abuse.

Abbreviations: $\mathrm{HR}$, hazard ratio; $\mathrm{Cl}$, confidence interval; ICU, intensive care unit; SOFA, sequential organ failure assessment; AIDS, acquired immune deficiency syndrome.

studies. ${ }^{5,6}$ Finally, differences in the response of the male and female immune systems to endotoxin and an association of female hormone levels with the clinical outcome have been identified in clinical studies. ${ }^{33-35}$ On the other hand, of perhaps even greater importance are the medical interventions received during the hospitalization of the patients, as well as the progression and management of comorbidities after discharge. Indeed, it was observed in our study that the need for mechanical ventilation and renal replacement therapy on the first day of ICU admission was significantly higher in male than in female patients.

To the best of our knowledge, we showed for the first time that female patients less than 50 years of age had a long-term survival advantage compared with male patients through interaction and stratified analysis for age ( $\geq 50$ and $<50$ years; the median age of menopause in the United States). ${ }^{36}$ Although no statistical difference was

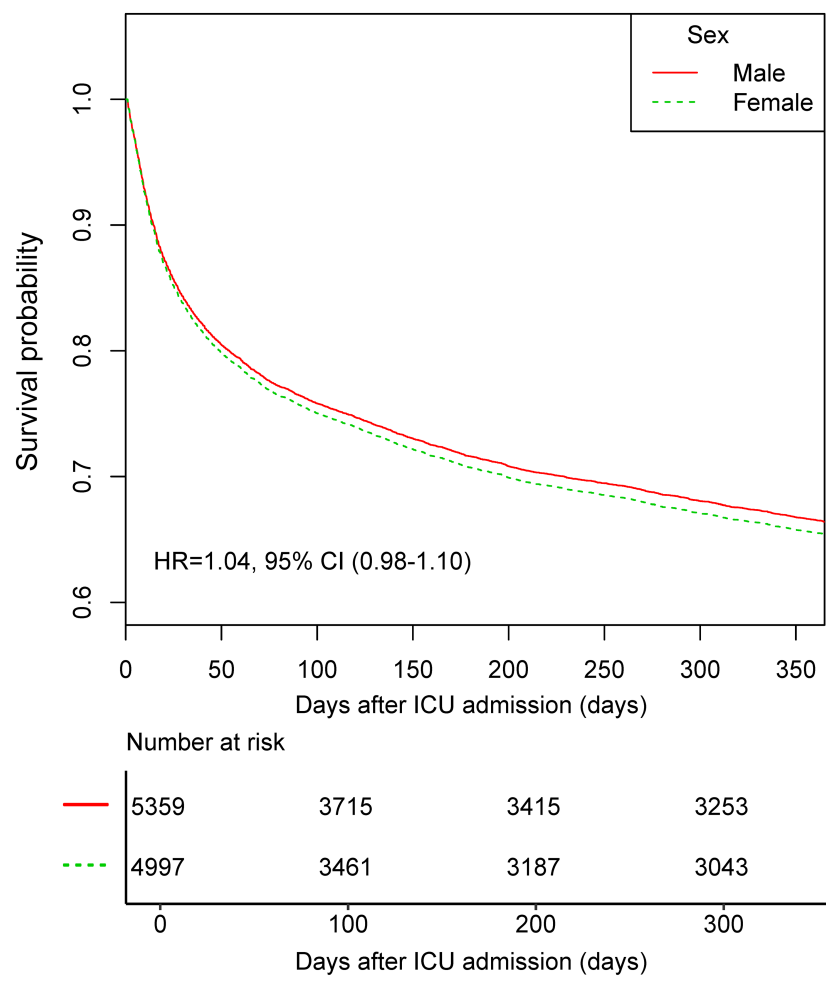

Figure 4 The I-year survival curve of the Cox regression model for participants with age $\geq 50$ years.

Notes: The Cox regression model for I-year mortality in female patients $\geq 50$ years of age compared to male patients had a result of $\mathrm{HR}=1.04(95 \% \mathrm{Cl} 0.98-1.10)$, after adjusting for age (years), infection site, SOFA, mechanical ventilation on first day, renal replacement therapy on first day, congestive heart failure, chronic pulmonary disease, valvular disease, peripheral vascular disease, hypertension, diabetes, liver disease, renal failure, AIDS, lymphoma, tumor, obesity, alcohol abuse, and drug abuse.

Abbreviations: $\mathrm{HR}$, hazard ratio; $\mathrm{Cl}$, confidence interval; ICU, intensive care unit; SOFA, sequential organ failure assessment; AIDS, acquired immune deficiency syndrome.

observed in the interaction for age and 28-day mortality, a reduction in 28-day mortality was almost certain in female patients younger than 50 years. Whether this is a crucial clue to a better prognosis due to female hormones or other factors needs further verification. Therefore, research on sex-based differences in patients with sepsis is worthy of attention.

Limitations remain to be pointed out, although a sufficiently large sample was included in our study. First, although previous studies have suggested that female hormones are associated with the immune system and endothelial cell function, we were unable to extract indicators related to hormone levels, inflammatory mediators, and cell function, making it impossible for us to assess the relationships. Second, the management of postdischarge comorbidities may have an impact on the longterm prognosis of patients; however, data on the treatment 
A

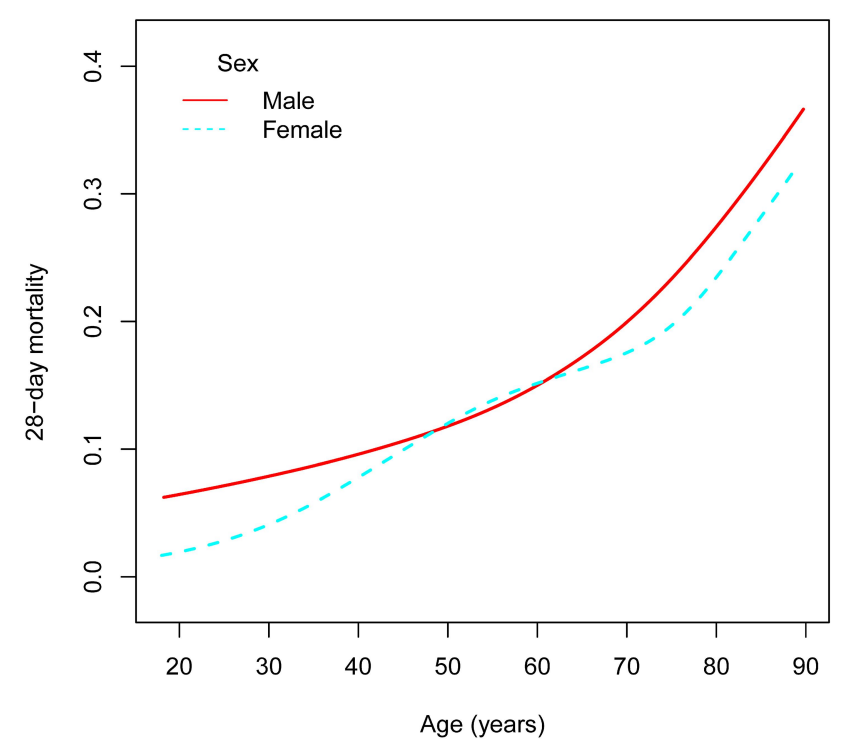

B

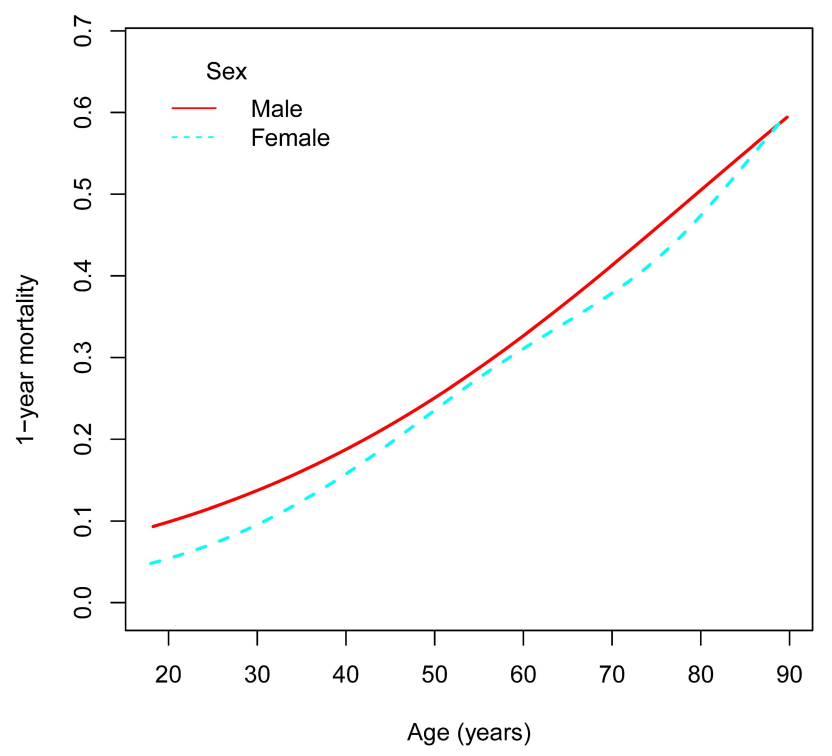

Figure 5 (A) Association of age with 28-day mortality in males and females. (B) Association of age with I-year mortality in males and females.

Notes: Adjust for infection site, SOFA, mechanical ventilation on first day, renal replacement therapy on first day, congestive heart failure, chronic pulmonary disease, valvular disease, peripheral vascular disease, hypertension, diabetes, liver disease, renal failure, AIDS, lymphoma, tumor, obesity, alcohol abuse, and drug abuse.

Abbreviations: SOFA, sequential organ failure assessment; AIDS, acquired immune deficiency syndrome.
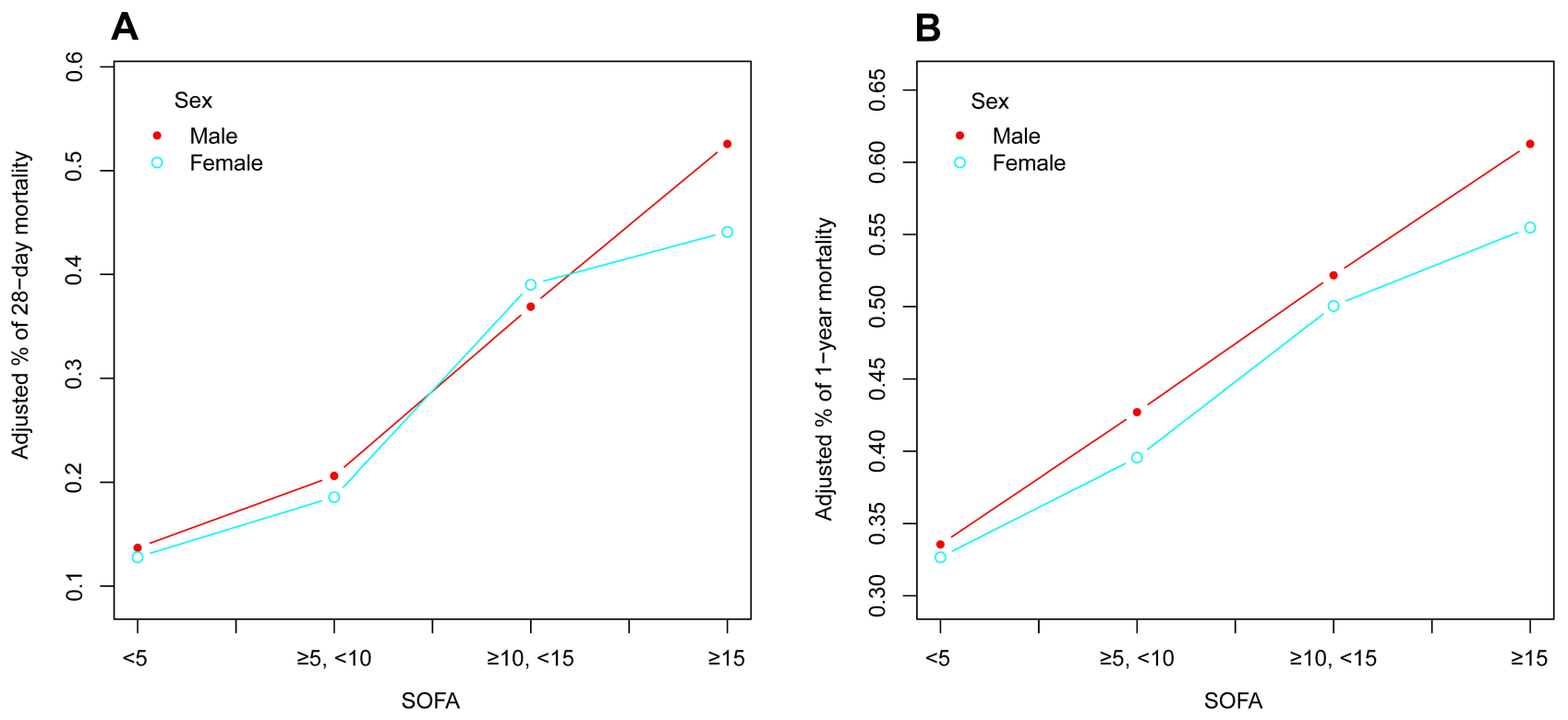

Figure 6 (A) Association of SOFA groups with 28-day mortality in males and females. (B) Association of SOFA groups with I-year mortality in males and females. Notes: Adjust for age (years), infection site, mechanical ventilation on first day, renal replacement therapy on first day, congestive heart failure, chronic pulmonary disease, valvular disease, peripheral vascular disease, hypertension, diabetes, liver disease, renal failure, AIDS, lymphoma, tumor, obesity, alcohol abuse, and drug abuse.

Abbreviations: SOFA, sequential organ failure assessment; AIDS, acquired immune deficiency syndrome.

and medication use for comorbidities are not available in the database. Therefore, we could not control for the confounding effect of these factors on the patients' outcomes. Third, selection bias is inherent in all retrospective studies. Nonetheless, the data in the database are independently measured and prospectively collected, making them not susceptible to manipulation. Forth, our findings should be interpreted with caution, since the results of the correlation analysis should not be misinterpreted as evidence of causality. Finally, the single-center study design may result in variation in external applicability. 


\section{Conclusions}

Among critically ill patients with sepsis, the 28-day and 1 -year mortality were significantly lower in females than in male patients. Notably, there was an interaction between age and sex. Nevertheless, whether female-associated hormones or other contributing factors affect the clinical outcomes of patients with sepsis needs to be further researched.

\section{Abbreviations}

ICU, intensive care unit; SID30, Elixhauser Comorbidity Index; SOFA, sequential organ failure assessment; AIDS, acquired immune deficiency syndrome; IQR, interquartile range; SQL, structured query language; HR, hazard ratio; $\mathrm{CI}$, confidence interval.

\section{Funding}

This work was supported by the National Natural Science Foundation of China [Grant number: 81670066]; the Major Science and Technology Planning Project of Guangdong Province, China [Grant number: 2016A020216009]; the Critical Care Research Funding of the Aesculap Academy (2017); the Guangdong Basic and Applied Basic Research Foundation, China [Grant number: 2019A1515011198].

\section{Disclosure}

The authors have no conflicts of interest to declare.

\section{References}

1. Singer M, Deutschman CS, Seymour CW, et al. The third international consensus definitions for sepsis and septic shock (sepsis-3). JAMA. 2016;315:801-810. doi:10.1001/jama.2016.0287

2. Lagu T, Rothberg MB, Shieh MS, Pekow PS, Steingrub JS, Lindenauer PK. Hospitalizations, costs, and outcomes of severe sepsis in the United States 2003 to 2007. Crit Care Med. 2012;40:754-761. doi:10.1097/CCM.0b013e318232db65

3. Rhee C, Dantes R, Epstein L, et al.; CDC Prevention Epicenter Program. Incidence and trends of sepsis in US hospitals using clinical vs claims data, 2009-2014. JAMA. 2017;318:1241-1249. doi:10.1001/ jama.2017.13836

4. Fleischmann C, Scherag A, Adhikari NK, et al.; International Forum of Acute Care Trialists. Assessment of global incidence and mortality of hospital-treated sepsis: current estimates and limitations. $\mathrm{Am}$ $J$ Respir Crit Care Med. 2016;193:259-272. doi:10.1164/ rccm.201504-0781OC

5. Zellweger R, Wichmann MW, Ayala A, Stein S, DeMaso CM, Chaudry IH. Females in proestrus state maintain splenic immune functions and tolerate sepsis better than males. Crit Care Med. 1997;25:106-110. doi:10.1097/00003246-199701000-00021

6. Angele MK, Wichmann MW, Ayala A, Cioffi WG, Chaudry IH. Testosterone receptor blockade after hemorrhage in males: restoration of the depressed immune functions and improved survival following subsequent sepsis. Arch Surg. 1997;132:1207-1214. doi:10.1001/ archsurg.1997.01430350057010
7. Angus DC, Linde-Zwirble WT, Lidicker J, Clermont G, Carcillo J, Pinsky MR. Epidemiology of severe sepsis in the United States: analysis of incidence, outcome, and associated costs of care. Crit Care Med. 2001;29:1303-1310. doi:10.1097/00003246-200107000-00002

8. Esper AM, Moss M, Lewis CA, Nisbet R, Mannino DM, Martin GS. The role of infection and comorbidity: factors that influence disparities in sepsis. Crit Care Med. 2006;34:2576-2582. doi:10.1097/01. CCM.0000239114.50519.0E

9. Wichmann MW, Inthorn D, Andress HJ, Schildberg FW. Incidence and mortality of severe sepsis in surgical intensive care patients: the influence of patient gender on disease process and outcome. Intensive Care Med. 2000;26:167-172. doi:10.1007/s001340050041

10. Martin GS, Mannino DM, Moss M. The effect of age on the development and outcome of adult sepsis. Crit Care Med. 2006;34:15-21. doi:10.1097/01.CCM.0000194535.82812.BA

11. Adrie C, Azoulay E, Francais A, et al. OutcomeRea Study Group. Influence of gender on the outcome of severe sepsis: a reappraisal. Chest. 2007;132:1786-1793. doi:10.1378/chest.07-0420

12. Nachtigall I, Tafelski S, Rothbart A, et al. Gender-related outcome difference is related to course of sepsis on mixed ICUs: a prospective, observational clinical study. Crit Care. 2011;15:R151. doi:10.1186/ cc10277

13. Eachempati SR, Hydo L, Barie PS. Gender-based differences in outcome in patients with sepsis. Arch Surg. 1999;134:1342-1347. doi:10.1001/archsurg.134.12.1342

14. Pietropaoli AP, Glance LG, Oakes D, Fisher SG. Gender differences in mortality in patients with severe sepsis or septic shock. Gend Med. 2010;7:422-437. doi:10.1016/j.genm.2010.09.005

15. Johnson AE, Pollard TJ, Shen L, et al. MIMIC-III, a freely accessible critical care database. Sci Data. 2016;3:160035. doi:10.1038/ sdata.2016.35

16. Johnson AEW, Aboab J, Raffa JD, et al. A comparative analysis of sepsis identification methods in an electronic database. Crit Care Med. 2018;46:494. doi:10.1097/CCM.0000000000002965

17. Lin S, Ge S, He W, Zeng M. Association of delayed time in the emergency department with the clinical outcomes for critically ill patients. $Q J$ Med. 1994;87:359-365. doi:10.1093/qjmed/hcaa192

18. Lin S, Ge S, He W, Zeng M. Association between body mass index and short-term clinical outcomes in critically ill patients with sepsis: a real-world study. Biomed Res Int. 2020;2020:5781913. doi:10.1155/ 2020/5781913

19. Lin S, He W, Zeng M. Association of diabetes and admission blood glucose levels with short-term outcomes in patients with critical illnesses. J Inflamm Res. 2020;13:1151-1166. doi:10.2147/JIR. S287510

20. Johnson A, Stone DJ, Celi LA, Pollard TJ. The MIMIC code repository: enabling reproducibility in critical care research. J Am Med Inform Assoc. 2017;25:32-39. doi:10.1093/jamia/ocx084

21. Steiner C, Elixhauser A, Schnaier J. The healthcare cost and utilization project: an overview. Eff Clin Pract. 2002;5:143-151.

22. Regitz-Zagrosek V, Oertelt-Prigione S, Prescott E, et al.; EUGenMed Cardiovascular Clinical Study Group. Gender in cardiovascular diseases: impact on clinical manifestations, management, and outcomes. Eur Heart J. 2015;37:24-34. doi:10.1093/eurheartj/ehv598

23. Reckelhoff JF. Gender differences in hypertension. Curr Opin Nephrol Hypertens. 2018;27:176-181. doi:10.1097/MNH.000000 0000000404

24. Di Giosia P, Giorgini P, Stamerra CA, Petrarca M, Ferri C, Sahebkar A. Gender differences in epidemiology, pathophysiology, and treatment of hypertension. Curr Atheroscler Rep. 2018;20:13. doi:10.1007/s11883-018-0716-z

25. Yu J, Mehran R, Grinfeld L, et al. Sex-based differences in bleeding and long term adverse events after percutaneous coronary intervention for acute myocardial infarction: three year results from the HORIZONS-AMI trial. Catheter Cardiovasc Interv. 2015;85:359-368. doi:10.1002/ccd.25630 
26. Raghavan D, Jain R. Increasing awareness of sex differences in airway diseases. Respirology. 2016;21:449-459. doi:10.1111/resp.12702

27. Pinkerton KE, Harbaugh M, Han MK, et al. Women and lung disease. Women and lung disease. Sex differences and global health disparities. Am J Respir Crit Care Med. 2015;192:11-16. doi:10.1164/rccm.201409-1740PP

28. Angele MK, Pratschke S, Hubbard WJ, Chaudry IH. Gender differences in sepsis: cardiovascular and immunological aspects. Virulence. 2014;5:12-19. doi:10.4161/viru.26982

29. Aulock SV, Deininger S, Draing C, Gueinzius K, Dehus O, Hermann C. Gender difference in cytokine secretion on immune stimulation with LPS and LTA. J Interferon Cytokine Res. 2006;26:887-892. doi:10.1089/jir.2006.26.887

30. Frink M, Pape HC, van Griensven M, Krettek C, Chaudry IH, Hildebrand F. Influence of sex and age on mods and cytokines after multiple injuries. Shock. 2007;27:151-156. doi:10.1097/01. shk.0000239767.64786.de

31. Spyridopoulos I, Sullivan AB, Kearney M, Isner JM, Losordo DW. Estrogen-receptor-mediated inhibition of human endothelial cell apoptosis. Estradiol as a survival factor. Circulation. 1997;95 (6):1505-1514. doi:10.1161/01.CIR.95.6.1505
32. Montt-Guevara MM, Palla G, Spina S, et al. Regulatory effects of estetrol on the endothelial plasminogen pathway and endothelial cell migration. Maturitas. 2017;99:1-9. doi:10.1016/j.maturitas.2017.02.005

33. van Eijk LT, Dorresteijn MJ, Smits P, van der Hoeven JG, Netea MG, Pickkers P. Gender differences in the innate immune response and vascular reactivity following the administration of endotoxin to human volunteers. Crit Care Med. 2007;35:1464-1469. doi:10.1097/01.CCM.0000266534.14262.E8

34. May AK, Dossett LA, Norris PR, et al. Estradiol is associated with mortality in critically ill trauma and surgical patients. Crit Care Med. 2008;36:62. doi:10.1097/01.CCM.0000292015.16171.6D

35. Angstwurm MWA, Gaertner R, Schopohl J. Outcome in elderly patients with severe infection is influenced by sex hormones but not gender. Crit Care Med. 2005;33:2786-2793. doi:10.1097/01. CCM.0000190242.24410.17

36. Gold EB, Bromberger J, Crawford S, et al. Factors associated with age at natural menopause in a multiethnic sample of midlife women. Am J Epidemiol. 2001;153(9):865-874. doi:10.1093/aje/153.9.865

\section{Publish your work in this journal}

The International Journal of General Medicine is an international, peer-reviewed open-access journal that focuses on general and internal medicine, pathogenesis, epidemiology, diagnosis, monitoring and treatment protocols. The journal is characterized by the rapid reporting of reviews, original research and clinical studies across all disease areas. The manuscript management system is completely online and includes a very quick and fair peer-review system, which is all easy to use. Visit http://www.dovepress.com/ testimonials.php to read real quotes from published authors. 